\title{
Chemical analysis of Vicarya in the Katsuta group, southwestern Japan
}

\author{
Y. TANAKA" AND M. TSUBOI \\ School of Science and Technology, Kwansei Gakuin \\ University, 2-1 Gakuin, Sanda, Hyogo, 669-1337, Japan \\ (correspondense: dxf06941@kwansei.ac.jp)
}

The Miocene Katsuta group is distributed in the Nagi area, Okayama prefecture, southwestern Japan. Many kinds of fossils including Vicarya, that is the index fossil of Miocene, have been found in this group. This study focuses on the chemical composition of Vicarya. Chemical analysis of fossil may provide information about fossilization process in the sediments. Furthermore, isotopic analysis such as ${ }^{87} \mathrm{Sr} /{ }^{86} \mathrm{Sr}$ provides environmental information of fossils. Therefore, the element of strontium is mainly adopted in this study. Samples were collected from the shell by micro-drilling technique and decomposed with acid. Elemental concentrations were determined by inductively coupled plasma mass spectrometry. Strontium content of shell tends to increase from top to the lower part of the shell. Vicarya has some hard spines on the shell, and X-Ray diffraction analysis revealed that both spine and non-spine parts are made of calcite. Aragonite and calcite are polymorphs of $\mathrm{CaCO}_{3}$. Calcite is known to be more stable at normal temperature and pressure [1]. The shell generally contains aragonite, and Vicarya's shell may have been changed from aragonite to calcite. The thickness of shell layer gradually becomes thinner from top to the lower part, and the grain size of filling mineral inside of the shell gradually becomes larger. Heterogeneous distribution of strontium within Vicarya's shell might be caused its growth process or its fossilization process such as phase transition of $\mathrm{CaCO}_{3}$ from aragonite to calcite.

[1] Ohta (1977) Gypsum \& Lime 146, 41-46. 